\title{
Surgical Management of Massive Irreparable Cuff Tears: Latissimus Dorsi Transfer for Posterosuperior Tears
}

\author{
Karl Wieser $^{1}$ - Lukas Ernstbrunner ${ }^{1}$ - Matthias A. Zumstein ${ }^{2,3}$ \\ Published online: 13 July 2020 \\ (C) The Author(s) 2020
}

\begin{abstract}
Purpose of Review This review aims to describe the role of the latissimus dorsi transfer (LDT) for patients with irreparable posterosuperior rotator cuff tears (RCTs).

Recent Findings Historically, the LDT has been performed as an open (double-incision) procedure for neurologically intact, relatively young patients with irreparable posterosuperior RCTs with disabling loss of active external rotation with or without impaired active elevation. The transferred tendon reconstitutes the posterior rotator cuff and force couple, respectively and thus has the potential to function effectively as an external rotator and humeral head depressor. Long-term results of the open technique have demonstrated in the majority of patients substantial and durable improvements in shoulder function and pain relief at the 10-year benchmark. With the advancements of arthroscopic surgery, the LDT was expanded to an arthroscopically assisted procedure with promising short-term results. In addition to adequate technical performance, the success of the procedure depends on preoperative factors, such as exclusion of glenohumeral osteoarthritis and acromial acetabularization; intact or reparable subscapularis tendon; intact (or hypertrophic) teres minor muscle; adequate preoperative activity of the latissimus dorsi; and normal or mild impairment of overhead function.

Summary The LDT (open or arthroscopically assisted) is a reliable treatment option for patients with massive, irreparable posterosuperior RCTs with disabling loss of active external rotation, with or without diminished overhead function and without advanced glenohumeral osteoarthritis. Precise patient selection is of tremendous importance in the success of the LDT.
\end{abstract}

Keywords Latissimus dorsi transfer - Tendon transfer · Arthroscopically assisted $\cdot$ Massive rotator cuff tear $\cdot$ Posterosuperior rotator cuff

This article is part of the Topical Collection on Surgical Management of Massive Irreparable Cuff Tears

Karl Wieser

karl.wieser@balgrist.ch

Lukas Ernstbrunner

lukas.ernstbrunner@balgrist.ch

Matthias A. Zumstein

m.zumstein@me.com

1 Department of Orthopedics, Balgrist University Hospital, University of Zurich, Forchstrasse 340 CH-8008 Zurich Switzerland

2 Shoulder, Elbow \& Orthopaedic Sports Medicine, Orthopaedics Sonnenhof; Inselspital, University of Berne, Bern Switzerland

3 SportsClinicNumber1, Bern Switzerland

\section{Introduction}

The generated forces of co-contracting rotator cuff muscles stabilize the humeral head within the glenoid concavity providing a stable fulcrum for optimal force transmission of the deltoid, rotator cuff, and periscapular muscles. Rupture of the rotator cuff tendons is common and might cause disruption of this delicately balanced force couple of anterior (subscapularis) and posterior (infraspinatus and teres minor) rotator cuff. With tear progression, joint compression forces and stability within the glenohumeral joint decrease, leading to diminished range of motion and strength.

The incidence of asymptomatic tears in patients over 60 years of age is high [1,2], and up to $40 \%$ of all rotator cuff tears (RCTs) are classified as massive [3-5]. A general definition of massive RCTs (mRCTs) includes involvement of two or more tendons [6]. If the RCT involves the posterosuperior cuff, 
typical functional deficits are weakness of abduction and external rotation with diminished overhead function $[7,8 \cdot \bullet]$. However, the clinical presentation of patients with posterosuperior $\mathrm{mRCTs}$ can vary widely from slight weakness and pain to pseudoparesis or even paralysis (PP) [9-11] with loss of control of the arm in space $[12,13]$. The hallmarks of chronic RCTs are atrophy [14], fatty infiltration [15], and myotendinous retraction [16], which can be assessed and quantified on MRI- or CT arthrography. Conventional radiographic changes associated with massive posterosuperior RCTs are cranial migration of the humeral head and progressive glenohumeral osteoarthritis (OA) $[12,13]$.

If fatty infiltration of the torn muscles is greater than stage 2 according to the Goutallier classification [15], and the acromiohumeral distance is less than $7 \mathrm{~mm}$, the probability for successful structural rotator cuff repair becomes so low that these mRCTs are generally considered irreparable (functionally irreparable rotator cuff tear (FIRCT)) [17]. With loss of the compressive force yielded through the rotator cuff, eccentric loads are placed upon the glenoid leading to erosion and early OA. Treatment should aim to restore more centred joint mechanics, which theoretically could slow the progression of OA, and to reconstitute the posterior rotator cuff and force couple, and thus shoulder function; these goals are particularly important in younger patients with high demands. The latissimus dorsi transfer (LDT) has been described to function as such external rotator and humeral head depressor [18] and is a reliable treatment option to alleviate pain and functional disability associated with irreparable posterosuperior RCTs in younger patients $[7,8 \bullet \bullet, 19-21]$.

\section{Clinical Presentation}

Clinical findings in patients with FIRTC can vary widely from slight weakness and pain to substantial loss of active shoulder function. Large tears after trauma oftentimes present with sudden loss of shoulder function [22], whereas chronic RCTs are usually associated with slow and progressive loss of function with increasing pain. Not all RCTs are symptomatic; if the remaining cuff and periscapular muscles are strong enough to compensate the torn rotator cuff tendons, FIRCTs can be associated with almost normal shoulder function and no pain.

The main disability experienced by many patients with a FIRCT is weakness with the arm away from the body. Posterosuperior FIRCTs typically cause weakness of elevation and external rotation [23]. There is a wide range of such weakness which ranges from slightly, nonquantifiable weakness to complete loss of active function of the respective muscle, socalled pseudoparalysis. The definition of pseudoparalysis is still under debate. Some surgeons use the term pseudoparalysis when there is no glenohumeral motion, and very limited elevation is provided through scapulothoracic motion only; pseudoparesis could be defined by the pain-free inability of actively abduct to $90^{\circ}$ with normal passive range of motion and absence of neurologic impairment [17]. Conversely, pseudoparalysis of external rotation is defined as complete loss of active external rotation strength in the presence of unrestricted passive external rotation and absence of neurologic impairment, which can be assessed using the Neer drop-arm sign [24], the external rotation lag sign [25], or the hornblower's sign [8, 26]. A functioning teres minor muscle is one of the factors associated with better outcome after LDT, and its function can be assessed through the so-called external rotation position 2-the arm in $90^{\circ}$ of abduction-while evaluating external rotation against resistance. A positive hornblower's sign is therefore likely associated with tear extension from the infraspinatus into the teres minor, which might negatively influence the final outcome of a LD tendon transfer.

Examination of the shoulder should also include subscapularis function (i.e. lift-off, belly-press, and bear hug tests). Obvious dynamic anterosuperior subluxation of the humerus upon resisted abduction is suggestive of an irreparable posterosuperior with additional subscapularis tear. In case of complete pseudoparalysis and/or a dynamic anterosuperior escape of the humeral head, which is most likely associated with an irreparable subscapularis tear [27-29], a LDT will not be able to substantially improve shoulder function and is therefore not indicated in such severely functionally impaired shoulders.

\section{Imaging}

True anteroposterior radiographs are useful to assess glenohumeral OA [30] and static superior migration of the humeral head. A static, not reducible, chronic acromiohumeral distance of $<7 \mathrm{~mm}$ on plain anteroposterior radiographs with the arm in neutral rotation has been reported to be strongly associated with FIRCTs [10, 17]. The critical shoulder angle (CSA) should be assessed as well, as a wide lateral extension of the acromion in the coronal plane is associated with worse outcome after LDT [20••]. Axillary lateral and scapular lateral radiographs should be assessed for anterior or posterior subluxation of the humeral head.

MR imaging is useful to assess the quality of rotator cuff tendons and its muscles. Fatty infiltration of the supraspinatus and infraspinatus muscles greater than stage 2 according to Goutallier [15] or the MRI modification thereof [31] is known to be associated with irreparability of RCTs [32, 33] (Fig. 1).

Integrity of the subscapularis and teres minor tendons and quality of the corresponding muscles should be assessed as they either need to be addressed intraoperatively and/or influence the clinical outcome. 


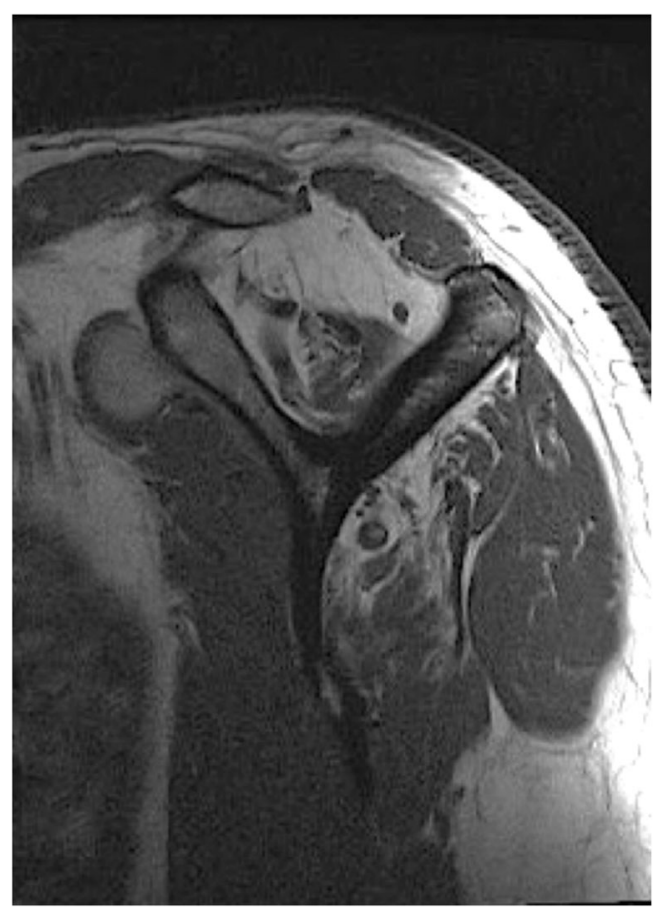

Fig. 1 Parasagittal T1-weighted MR imaging showing advanced fatty infiltration of the supraspinatus (with atrophy) and infraspinatus muscles. Muscles of the subscapularis and teres minor show no degeneration

\section{Treatment Options}

\section{Nonoperative Treatment}

Although there is no evidence that conservative treatment alters the natural history of FIRCTs, good clinical results after conservative treatment have been reported [34]. If the cuff tear is irreparable, as long as functional impairment and pain are tolerated, nonoperative management including physiotherapy, nonsteroidal anti-inflammatory medications and corticosteroid injections can be considered.

\section{Surgical Treatment}

Patients with FIRCT who fail nonoperative management can be considered for surgical treatment, which may include arthroscopic debridement with biceps tenotomy or tenodesis, partial RCT repair with or without augmentation, superior capsular reconstruction, tendon transfers, and reverse total shoulder arthroplasty (RTSA) [8, 35-38]. Arthroscopic debridement and partial repair have been proved to provide reliable pain relief $[39,40]$, but these procedures do not seem to halt or substantially decrease the progression of glenohumeral OA [40, 41]. There is good evidence to suggest that successful repair of massive RCTs provides excellent clinical long-term results and that progression of glenohumeral OA can be decelerated $[6,42-44]$. RTSA has been shown to provide satisfactory long-term results for massive, irreparable RCTs in elderly and even in younger patients after failed rotator cuff repair [10, 11, 17, 45]. However, the biomechanics of RTSA does not allow for restoration of a good arc of external rotation in patients with pseudoparalysis of external rotation. Furthermore, in young and active patients without signs of OA, joint-preserving options such as tendon transfers should be considered beforehand.

When considering a tendon transfer, the following principles should be fulfilled: (1) the transferred muscle should be expendable without compromising the donor site, (2) the transferred and recipient muscle should have a similar excursion and tension, and (3) the line of pull (vector) of the transferred tendon and recipient muscle should be as similar as possible [18].

\section{Latissimus Dorsi Transfer}

\section{Indications}

The success of the LDT depends on proper patient selection. The subscapularis tendon should be intact or reparable $[20 \bullet \cdot$. The inferior functional results after LDT with a dysfunctional subscapularis are explained by insufficient centring of the humeral head during abduction and elevation [46 ${ }^{\circ}$. Inferior results have also been observed when chronic pseudoparalysis of active anterior elevation was present, and also when the teres minor showed advanced fatty infiltration [19, 47]. Failure of the LDT can be anticipated when glenohumeral OA or acromial acetabularization are present [48•]. Details about relative and absolute contraindications for LDT are summarized in Table 1.

\section{Anatomy and Biomechanics}

The latissimus dorsi is triangle-shaped and has a broad origin from the sacrum, posterior iliac crest, spinous processes of T7L5, and ribs 9-12. It inserts onto the intertubercular groove between the pectoralis major anteriorly and the teres major posteriorly [49॰]. It is innervated by the thoracodorsal nerve (C6-C8), from the posterior cord of the brachial plexus. The thoracodorsal artery provides its blood supply. The thoracodorsal

Table 1 Relative and absolute contraindications for latissimus dorsi tendon transfer

\begin{tabular}{ll}
\hline Relative contraindications & Absolute contraindications \\
\hline Advanced age & Deltoid insufficiency \\
Severe fatty infiltration of TMin & Advanced glenohumeral osteoarthritis \\
SSC repair under tension & Irreparable SSC tear \\
Poor bone quality & Infection \\
Poor compliance & Complete pseudoparalysis of abduction \\
& Dynamic anterosuperior escape \\
\hline
\end{tabular}

TMin, teres minor; SSC, subscapularis 
artery and nerve run together as a neurovascular pedicle, which enters the muscle approximately $2 \mathrm{~cm}$ medial to the musculotendinous border [50॰. Proximal to the insertion of the latissimus dorsi runs the axillary nerve. The radial nerve runs inferior and medial to the latissimus dorsi insertion.

The latissimus dorsi internally rotates, adducts, and extends the humerus. When the latissimus dorsi tendon is transferred to the greater tuberosity for the management of a FIRCT, it reconstitutes the posterior rotator cuff and force couple, respectively. Thus, it has the potential to function effectively as an external rotator and humeral head depressor that is counterbalanced by the deltoid and intact subscapularis $[7,8,18]$.

\section{Surgical Technique}

In the original description of Gerber et al. [8••], an open double-incision approach involved an approximately $12 \mathrm{~cm}$ long superior approach to the rotator cuff with the sagittal incision spanning from the scapular spine to $5 \mathrm{~cm}$ ventral to the anterior acromion. The incision is just medial and parallel to the lateral acromion, and the middle deltoid is detached with a small bone chip from the lateral acromion. The remaining rotator cuff is evaluated and repaired when feasible.

With the arm in full elevation, a second L-shaped incision of approximately $20 \mathrm{~cm}$ is performed just over the anterior border of latissimus dorsi muscle belly in the axilla. The latissimus dorsi muscle lies anterior to the teres major, and the interval between these two muscles is dissected. The long and broad but very thin tendon of the latissimus dorsi is then sharply released from the humerus and reinforced with two high-strength sutures. A passage between the posterior deltoid and the teres minor is established for the tendon transfer. The latissimus tendon is transferred through the passage and secured at the anterior portion of the greater tuberosity with the arm in $45^{\circ}$ of abduction and $45^{\circ}$ of external rotation. The middle deltoid is repaired to the lateral acromion using transosseous techniques.

A less invasive technique is the posterior single-incision approach described by Habermeyer et al. [51•]. The main advantage of this procure is that the deltoid muscle is not detached, and the posterior rotator cuff is directly visualized through a posterior $\mathrm{V}$-shaped incision. The main disadvantage is that the anterosuperior rotator cuff cannot be visualized or repaired when necessary.

Recently, with the advancements of arthroscopic surgery, the LDT was expanded to an arthroscopically assisted [52 ${ }^{\bullet}$ or even all-arthroscopic procedure [53•].

With the arthroscope in the posterior standard portal, the anterior portion of the greater tuberosity is prepared for LDT fixation. Then with the arthroscope in the lateral portal, the passage between the deltoid and the teres minor is established with the shaver and radio frequency ablation devices.

A shuttling suture or tape is positioned in the interval for later passage of the harvested latissimus dorsi tendon. Finally, after axially harvesting and passing, the tendon is fixed with at least two knotless anchors to the anterior portion of the greater tuberosity (Fig. 2).

One disadvantage of the all-arthroscopic procedure is the inability to perform a proper release of the muscle belly from its connective tissue, making it almost impossible to transfer the tendon to the desired fixation point at the anterior part of the greater tuberosity and leading to a high tension of the tendon-to-bone fixation. In addition, the all-arthroscopic LDT is associated with a very steep learning curve.

The authors therefore prefer the arthroscopic-assisted LDT as it offers some potential benefits over the open technique: (1) iatrogenic deltoid insufficiency can be avoided and the remaining posterosuperior rotator cuff as well as subscapularis tears can be easily diagnosed and repaired. (2) The passage of the tendon between the posterior deltoid muscle and the teres minor can be prepared and visualized with the arthroscope, making it easier to define this interval in comparison with the axillary incision. (3) If desired, the release of the latissimus dorsi tendon can be performed arthroscopically, therefore reducing the axillary incision length, which is then only needed for release of the muscle belly and identification of the intermuscular passage.

Postoperatively, the shoulder is positioned on an abduction brace for 6 weeks. Postoperative physiotherapy is started immediately, with only passive range of motion for the first 6 weeks. After 6 weeks, the abduction brace is discontinued and active range of motion is initiated. After 3 months, gradual strengthening exercises can be initiated with unrestricted strengthening exercises added after 6 months.

\section{Clinical and Radiographic Outcome}

Long-term results of the open technique of Gerber et al. demonstrated durable improvements in shoulder function and pain relief, with $74 \%$ of the patients rating their subjective outcome as good to excellent at the 10-year benchmark [20•0]. The postoperative subjective shoulder value averaged at $70 \%$ and mean active external rotation was improved from $18^{\circ}$ to $30^{\circ}$. Also, active overhead function was significantly improved 10 years postoperatively and averaged beyond $120^{\circ}$. In this series, 32 patients had an increase of the SSV of more than $30 \%$, whereas 14 patients had an increase of the SSV of less than $30 \%$ and were considered to have an unsatisfactory outcome. Those patients with a poor outcome had more fatty degeneration of the teres minor, a higher rate of subscapularis insufficiency, and a higher rate of an inactive LDT. Further subgroup analysis showed that patients with a higher CSA had significantly lower subjective and objective outcome scores. Patients with a CSA of less than $36^{\circ}$ scored with $91 \%$ relative Constant score, significantly higher than the subgroup with a CSA of more than $36^{\circ}$, which had $71 \%$. However, the general strong improvement in shoulder function and pain relief is consistent with the long-term results of El-Azab et al. [48•], who reported a satisfaction rate of $86 \%$. In this cohort 
Fig. 2 a Inraoperative photo documentation of latissimus dorsi tendon transfer (LDT). Through an open axillary approach, the long and broad but very thin tendon of the latissimus dorsi is sharply released from the humerus and reinforced with two high-strength sutures. b A passage between the posterior deltoid and the teres minor is established arthroscopically (with the scope in the lateral portal), and a shuttling band (blue) is positioned in the interval for passage of the LDT. $\mathbf{c}$ The reinforced latissimus tendon is then shuttled through the passage to the prepared anterior portion of the greater tuberosity. d and e Through two cannulas in each of the two high anterolateral portals, the tendon is refixated with at least two knotless PEEK anchors to the anterior portion of the greater tuberosity. $\mathbf{f}$ The tendon is tightened through the knotless anchors until it reaches the anchor holes
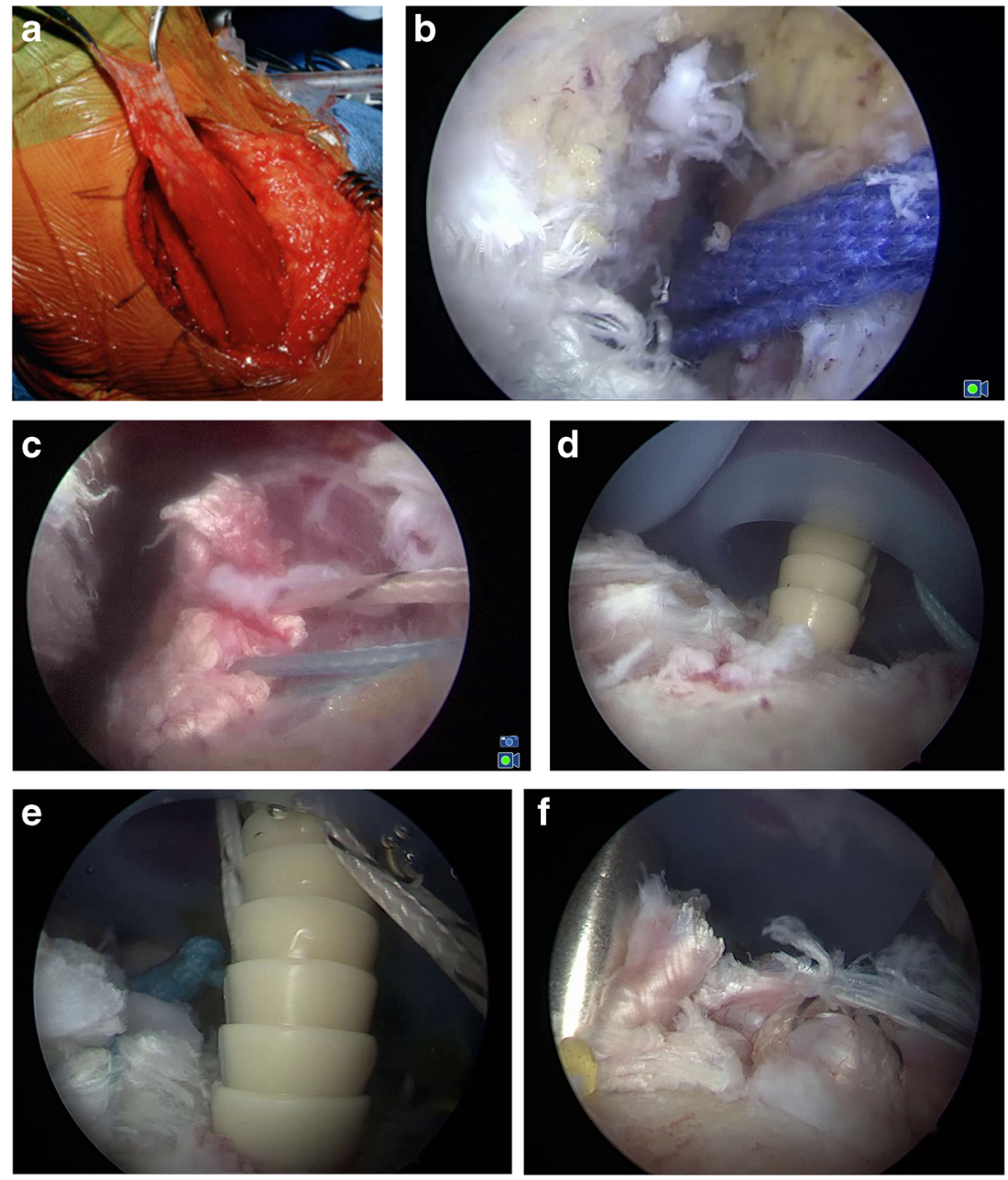

of 115 shoulders, the failure rate of the open LDT was $10 \%$, and $4 \%$ needed reoperation to implant a RTSA [48 $]$. Although substantial progression of OA was observed in $11 \%$ of the patients 10 years postoperatively [20••], the necessity of RTSA can be reportedly delayed [54•]. Older patients and patients with a transfer after a failed $\mathrm{RC}$ repair had a slight but significant inferior clinical outcome compared with the patients with a primary LDT. Those shoulders that had the LDT in combination with subscapularis repair showed actually no difference in the clinical outcome compared with those with an intact subscapularis.

Although no long-term results of the arthroscopicassisted LDT are available, short-term results are comparable with the open techniques with significantly improved shoulder function and reliable pain relief [21•]. Complications of the arthroscopic and open techniques are comparably low and include postoperative hematoma, frozen shoulder, nerve injuries, infection, and failure of the tendon transfer $[21,55]$. In one study, the overall complication rate of 258 pooled arthroscopic-assisted LDTs was $7.3 \%$, including tendon rupture $(2.7 \%)$, deep infection $(2.3 \%)$, postoperative hematoma $(2 \%)$, and transient brachial plexus palsy $(0.4 \%)$ [21•].

\section{Conclusions}

The LDT (open or arthroscopically assisted) is a reliable treatment option with substantial and durable improvement of pain and shoulder function for patients with massive, irreparable posterosuperior RCT with disabling loss of active external rotation, with or without diminished overhead function, and without glenohumeral osteoarthritis. The long-term failure rate is about $10 \%$, and $4 \%$ of patients need revision to RTSA after 10 years. Careful patient selection is of tremendous importance in the success of the LDT. Teres minor degeneration, associated irreparable subscapularis tears, a high CSA, and advanced age are risk factors for unsatisfactory outcome.

Funding Information Open access funding provided by University of Zurich.

\section{Compliance with Ethical Standards}

Conflict of Interest Karl Wieser declares that he has no conflict of interest related to this study.

Lukas Ernstbrunner declares that he has no conflict of interest related to this study. 
Matthias Zumstein declares that he has no conflict of interest related to this study.

Open Access This article is licensed under a Creative Commons Attribution 4.0 International License, which permits use, sharing, adaptation, distribution and reproduction in any medium or format, as long as you give appropriate credit to the original author(s) and the source, provide a link to the Creative Commons licence, and indicate if changes were made. The images or other third party material in this article are included in the article's Creative Commons licence, unless indicated otherwise in a credit line to the material. If material is not included in the article's Creative Commons licence and your intended use is not permitted by statutory regulation or exceeds the permitted use, you will need to obtain permission directly from the copyright holder. To view a copy of this licence, visit http://creativecommons.org/licenses/by/4.0/.

\section{References}

Papers of particular interest, published recently, have been highlighted as:

- Of importance

•- Of major importance

1. Milgrom C, Schaffler M, Gilbert S, van Holsbeeck M. Rotator-cuff changes in asymptomatic adults. The effect of age, hand dominance and gender. J Bone Joint Surg Bri. 1995;77(2):296-8.

2. Sher JS, Uribe JW, Posada A, Murphy BJ, Zlatkin MB. Abnormal findings on magnetic resonance images of asymptomatic shoulders. J Bone Joint Surg Am. 1995;77(1):10-5.

3. Ellman H, Hanker G, Bayer M. Repair of the rotator cuff. Endresult study of factors influencing reconstruction. J Bone Joint Surg Am. 1986;68(8):1136-44.

4. Ellman H, Kay SP, Wirth M. Arthroscopic treatment of fullthickness rotator cuff tears: 2- to 7-year follow-up study. Arthroscopy: the journal of arthroscopic \& related surgery: official publication of the Arthroscopy Association of North America and the International Arthroscopy Association. 1993;9(2):195-200.

5. Habermeyer P, Krieter C, Tang KL, Lichtenberg S, Magosch P. A new arthroscopic classification of articular-sided supraspinatus footprint lesions: a prospective comparison with Snyder's and Ellman's classification. Journal of shoulder and elbow surgery / American Shoulder and Elbow Surgeons [et al]. 2008;17(6):90913.

6. Gerber C, Fuchs B, Hodler J. The results of repair of massive tears of the rotator cuff. J Bone Joint Surg Am. 2000;82(4):505-15.

7. Gerber C. Latissimus dorsi transfer for the treatment of irreparable tears of the rotator cuff. Clinical orthopaedics and related research. 1992;(275):152-60.

8.• Gerber C, Vinh TS, Hertel R, Hess CW. Latissimus dorsi transfer for the treatment of massive tears of the rotator cuff. A preliminary report. Clinical orthopaedics and related research. 1988;(232):5161 Landmark study as it is the first description of the LDT for massive posterosuperior rotator cuff tears.

9. Ernstbrunner L, Andronic O, Grubhofer F, Camenzind RS, Wieser $\mathrm{K}$, Gerber C. Long-term results of reverse total shoulder arthroplasty for rotator cuff dysfunction: a systematic review of longitudinal outcomes. Journal of shoulder and elbow surgery / American Shoulder and Elbow Surgeons [et al]. 2019.

10. Ernstbrunner L, Suter A, Catanzaro S, Rahm S, Gerber C. Reverse total shoulder arthroplasty for massive, irreparable rotator cuff tears before the age of 60 years: long-term results. J Bone Joint Surg Am. 2017;99(20):1721-9.

11. Gerber C, Canonica S, Catanzaro S, Ernstbrunner L. Longitudinal observational study of reverse total shoulder arthroplasty for irreparable rotator cuff dysfunction: results after 15 years. Journal of shoulder and elbow surgery / American Shoulder and Elbow Surgeons [et al]. 2018.

12. Jost B, Zumstein M, Pfirrmann CW, Gerber C. Long-term outcome after structural failure of rotator cuff repairs. J Bone Joint Surg Am. 2006;88(3):472-9.

13. Jost B, Pfirrmann CW, Gerber C, Switzerland Z. Clinical outcome after structural failure of rotator cuff repairs. J Bone Joint Surg Am. 2000;82(3):304-14.

14. Zanetti M, Gerber C, Hodler J. Quantitative assessment of the muscles of the rotator cuff with magnetic resonance imaging. Investig Radiol. 1998;33(3):163-70.

15. Goutallier D, Postel JM, Bernageau J, Lavau L, Voisin MC. Fatty muscle degeneration in cuff ruptures. Pre- and postoperative evaluation by CT scan. Clin Orthop Relat Res. 1994;304:78-83.

16. Meyer DC, Wieser K, Farshad M, Gerber C. Retraction of supraspinatus muscle and tendon as predictors of success of rotator cuff repair. Am J Sports Med. 2012;40(10):2242-7.

17. Werner CM, Steinmann PA, Gilbart M, Gerber C. Treatment of painful pseudoparesis due to irreparable rotator cuff dysfunction with the Delta III reverse-ball-and-socket total shoulder prosthesis. J Bone Joint Surg Am. 2005;87(7):1476-86.

18. Elhassan B, Bishop A, Shin A, Spinner R. Shoulder tendon transfer options for adult patients with brachial plexus injury. J Hand Surg. 2010;35(7):1211-9.

19. Gerber C, Maquieira G, Espinosa N. Latissimus dorsi transfer for the treatment of irreparable rotator cuff tears. The Journal of bone and joint surgery American. 2006;88(1):113-20 First mid- to long-term results of the open LDT.

20.• Gerber C, Rahm SA, Catanzaro S, Farshad M, Moor BK. Latissimus dorsi tendon transfer for treatment of irreparable posterosuperior rotator cuff tears: long-term results at a minimum follow-up of ten years. The Journal of bone and joint surgery American. 2013;95(21):1920-6 Landmark study; first longterm results of the open LDT.

21. Memon M, Kay J, Quick E, Simunovic N, Duong A, Henry P, et al. Arthroscopic-assisted latissimus dorsi tendon transfer for massive rotator cuff tears: a systematic review. Orthopaedic journal of sports medicine. 2018;6(6):2325967118777735 Pooled short-term results of the arthroscopic LDT.

22. Spross C, Behrens G, Dietrich TJ, Olaf Kim CH, Puskas GJ, Zdravkovic V, et al. Early arthroscopic repair of acute traumatic massive rotator cuff tears leads to reliable reversal of pseudoparesis: clinical and radiographic outcome. Arthroscopy: the journal of arthroscopic \& related surgery: official publication of the Arthroscopy Association of North America and the International Arthroscopy Association. 2019;35(2):343-50.

23. Gerber C, Blumenthal S, Curt A, Werner CM. Effect of selective experimental suprascapular nerve block on abduction and external rotation strength of the shoulder. Journal of shoulder and elbow surgery / American Shoulder and Elbow Surgeons [et al]. 2007;16(6):815-20.

24. Neer CS 2nd. Shoulder reconstruction. W.B.: Saunders; 1990.

25. Hertel R, Ballmer FT, Lombert SM, Gerber C. Lag signs in the diagnosis of rotator cuff rupture. Journal of shoulder and elbow surgery / American Shoulder and Elbow Surgeons [et al]. 1996;5(4):307-13.

26. Walch G, Boulahia A, Calderone S, Robinson AH. The 'dropping' and 'hornblower's' signs in evaluation of rotator-cuff tears. J Bone Joint Surg Br. 1998;80(4):624-8.

27. Collin P, Matsumura N, Ladermann A, Denard PJ, Walch G. Relationship between massive chronic rotator cuff tear pattern 
and loss of active shoulder range of motion. Journal of shoulder and elbow surgery / American Shoulder and Elbow Surgeons [et al]. 2014;23(8):1195-202.

28. Wieser K, Rahm S, Schubert M, Fischer MA, Farshad M, Gerber C, et al. Fluoroscopic, magnetic resonance imaging, and electrophysiologic assessment of shoulders with massive tears of the rotator cuff. Journal of shoulder and elbow surgery / American Shoulder and Elbow Surgeons [et al]. 2015;24(2):288-94.

29. Ernstbrunner L, El Nashar R, Bouaicha S, Wieser K, Gerber C. Scapular morphologic characteristics and rotator cuff tear pattern are independently associated with chronic pseudoparalyis: a matched-pair analysis of patients with massive rotator cuff tears. Am J Sports Med. 2020;363546520929353.

30. Hamada K, Fukuda H, Mikasa M, Kobayashi Y. Roentgenographic findings in massive rotator cuff tears. A long-term observation Clinical orthopaedics and related research. 1990;254:92-6.

31. Fuchs B, Weishaupt D, Zanetti M, Hodler J, Gerber C. Fatty degeneration of the muscles of the rotator cuff: assessment by computed tomography versus magnetic resonance imaging. Journal of shoulder and elbow surgery / American Shoulder and Elbow Surgeons [et al]. 1999;8(6):599-605.

32. Gladstone JN, Bishop JY, Lo IK, Flatow EL. Fatty infiltration and atrophy of the rotator cuff do not improve after rotator cuff repair and correlate with poor functional outcome. Am J Sports Med. 2007;35(5):719-28.

33. Goutallier D, Postel JM, Gleyze P, Leguilloux P, Van Driessche S. Influence of cuff muscle fatty degeneration on anatomic and functional outcomes after simple suture of full-thickness tears. Journal of shoulder and elbow surgery / American Shoulder and Elbow Surgeons [et al]. 2003;12(6):550-4.

34. Zingg PO, Jost B, Sukthankar A, Buhler M, Pfirrmann CW, Gerber C. Clinical and structural outcomes of nonoperative management of massive rotator cuff tears. J Bone Joint Surg Am. 2007;89(9):1928-34.

35. Kempf JF, Gleyze P, Bonnomet F, Walch G, Mole D, Frank A, et al. A multicenter study of 210 rotator cuff tears treated by arthroscopic acromioplasty. Arthroscopy: the journal of arthroscopic \& related surgery: official publication of the Arthroscopy Association of North America and the International Arthroscopy Association. 1999;15(1):56-66.

36. Mihata T, Lee TQ, Watanabe C, Fukunishi K, Ohue M, Tsujimura $\mathrm{T}$, et al. Clinical results of arthroscopic superior capsule reconstruction for irreparable rotator cuff tears. Arthroscopy: the journal of arthroscopic \& related surgery: official publication of the Arthroscopy Association of North America and the International Arthroscopy Association. 2013;29(3):459-70.

37. Wellmann M, Lichtenberg S, da Silva G, Magosch P, Habermeyer P. Results of arthroscopic partial repair of large retracted rotator cuff tears. Arthroscopy: the journal of arthroscopic \& related surgery: official publication of the Arthroscopy Association of North America and the International Arthroscopy Association. 2013;29(8):1275-82.

38. Ernstbrunner L, Wieser K, Catanzaro S, Agten CA, Fornaciari P, Bauer DE, et al. Long-term outcomes of pectoralis major transfer for the treatment of irreparable subscapularis tears: results after a mean follow-up of 20 years. J Bone Joint Surg Am. 2019.

39. Iagulli ND, Field LD, Hobgood ER, Ramsey JR, Savoie FH 3rd. Comparison of partial versus complete arthroscopic repair of massive rotator cuff tears. Am J Sports Med. 2012;40(5):1022-6.

40. Walch G, Edwards TB, Boulahia A, Nove-Josserand L, Neyton L, Szabo I. Arthroscopic tenotomy of the long head of the biceps in the treatment of rotator cuff tears: clinical and radiographic results of 307 cases. Journal of shoulder and elbow surgery / American Shoulder and Elbow Surgeons [et al]. 2005;14(3):238-46.

41. Boileau P, Baque F, Valerio L, Ahrens P, Chuinard C, Trojani C. Isolated arthroscopic biceps tenotomy or tenodesis improves symptoms in patients with massive irreparable rotator cuff tears. J Bone Joint Surg Am. 2007;89(4):747-57.
42. Adamson GJ, Tibone JE. Ten-year assessment of primary rotator cuff repairs. Journal of shoulder and elbow surgery / American Shoulder and Elbow Surgeons [et al]. 1993;2(2):57-63.

43. Bedi A, Dines J, Warren RF, Dines DM. Massive tears of the rotator cuff. J Bone Joint Surg Am. 2010;92(9):1894-908.

44. Burkhart SS. Arthroscopic treatment of massive rotator cuff tears. Clinical results and biomechanical rationale Clinical orthopaedics and related research. 1991;267:45-56.

45. Guery J, Favard L, Sirveaux F, Oudet D, Mole D, Walch G. Reverse total shoulder arthroplasty. Survivorship analysis of eighty replacements followed for five to ten years. J Bone Joint Surg Am. 2006;88(8):1742-7.

46. Werner CM, Zingg PO, Lie D, Jacob HA, Gerber C. The biomechanical role of the subscapularis in latissimus dorsi transfer for the treatment of irreparable rotator cuff tears. Journal of shoulder and elbow surgery / American Shoulder and Elbow Surgeons [et al]. 2006;15(6):736-42 Important study for understanding of crucial factors associated with outcome after LDT.

47. Costouros JG, Espinosa N, Schmid MR, Gerber C. Teres minor integrity predicts outcome of latissimus dorsi tendon transfer for irreparable rotator cuff tears. Journal of shoulder and elbow surgery / American Shoulder and Elbow Surgeons [et al]. 2007;16(6):72734 Important study for understanding of crucial factors associated with outcome after LDT.

48. El-Azab HM, Rott O, Irlenbusch U. Long-term follow-up after latissimus dorsi transfer for irreparable posterosuperior rotator cuff tears. The Journal of bone and joint surgery American. 2015;97(6): 462-9 Another important long-term study of the LDT.

49. Ranade AV, Rai R, Rai AR, Dass PM, Pai MM, Vadgaonkar R. Variants of latissimus dorsi with a perspective on tendon transfer surgery: an anatomic study. Journal of shoulder and elbow surgery / American Shoulder and Elbow Surgeons [et al]. 2018;27(1):16771 Important anatomical study with perspective on LDT.

50. Bartlett SP, May JW Jr, Yaremchuk MJ. The latissimus dorsi muscle: a fresh cadaver study of the primary neurovascular pedicle. Plastic and reconstructive surgery. 1981;67(5):631-6 Important anatomical study with perspective on LDT.

51. Habermeyer P, Magosch P, Rudolph T, Lichtenberg S, Liem D. Transfer of the tendon of latissimus dorsi for the treatment of massive tears of the rotator cuff: a new single-incision technique. The Journal of bone and joint surgery British. 2006;88(2):208-12 Alternative surgical approach for the LDT.

52. Gervasi E, Causero A, Parodi PC, Raimondo D, Tancredi G. Arthroscopic latissimus dorsi transfer. Arthroscopy: the journal of arthroscopic \& related surgery: official publication of the Arthroscopy Association of North America and the International Arthroscopy Association. 2007;23(11):1243 e1-4 Surgical technique of arthroscopic-assisted LDT.

53. Cutbush K, Peter NA, Hirpara K. All-arthroscopic latissimus dorsi transfer. Arthrose Tech. 2016;5(3):e607-13 Surgical technique of all-arthroscopic LDT.

54. Warner JJ, Parsons IM. Latissimus dorsi tendon transfer: a comparative analysis of primary and salvage reconstruction of massive, irreparable rotator cuff tears. Journal of shoulder and elbow surgery / American Shoulder and Elbow Surgeons [et al]. 2001;10(6):514-21.

55. Castricini R, De Benedetto M, Familiari F, De Gori M, De Nardo $\mathrm{P}$, Orlando N, et al. Functional status and failed rotator cuff repair predict outcomes after arthroscopic-assisted latissimus dorsi transfer for irreparable massive rotator cuff tears. Journal of shoulder and elbow surgery / American Shoulder and Elbow Surgeons [et al]. 2016;25(4):658-65 Benchmark outcome study about the arthroscopic-assisted LDT.

Publisher's note Springer Nature remains neutral with regard to jurisdictional claims in published maps and institutional affiliations. 